\title{
後大脳動脈末梢部動脈瘤 $\left(\mathrm{P}_{3}\right.$ segment)の 1 手術例 — Posterior subtemporal approach の有用性一
}

\author{
岡部 慎一, 河野 拓司, 野々垣洋一 \\ 原田 洋一, 遠藤 聖, 鎌田 健一
}

\section{An Operative Case of the $P_{3}$ Segment Aneurysm of the Posterior Cerebral Artery Treated with the Posterior Subtemporal Approach}

Shinichi OKaBe, M.D., Takuji KoHno, M.D., Yoichi Nonogaki, M.D., Yoichi Harada, M.D., Kiyoshi Endo, M.D., and Kenichi Kamata, M.D.

Seirei Memorial Hospital for Neurosurgery, Hitachi, Japan

Summary: We present a surgical case of distal posterior cerebral artery (PCA) aneurysms with the advantages of the posterior subtemporal approach.

A 68-year-old woman had a ruptured left $\mathrm{P}_{3}$ segment aneurysm, unruptured left $\mathrm{P}_{2}$ segment and left middle cerebral artery (MCA) aneurysms. On the first day, the MCA aneurysm was clipped with irrigation and washout of dense subarachnoid clots in the left Sylvian fissure. On the fifth day, the left PCA aneurysms were clipped via the posterior subtemporal route. We could easily reach the ruptured aneurysm located in the quadrigeminal cistern along the tentorial surface via the wide space behind the vein of Labbé. After VP shunting, the woman was discharged with no neurological deficits.

This approach to the distal PCA aneurysms provides early observation of the proximal trunk of the PCA, minimal retraction of the temporo-occipital lobe and safe manipulation of the vein of Labbé.

\section{Key words: \\ - posterior cerebral artery aneurysm \\ - subarachnoid hemor- rhage \\ - posterior subtemporal approach \\ - aneurysmal surgery}

Surg Cereb Stroke (Jpn) 25: 476-480, 1997

\section{はじめに}

後大脳動脈 (posterior cerebral artery, 以下PCA)末梢動 脈瘤は，深部に位置するため手術接近法に関しては種々の 方法が提唱されている。今回，PCA末梢の多発動脈瘤に 対して, Labbé静脈の後方よりテント上面に沿った approach を行ったところ, PCA 本幹の早期確保, 動脈瘤
への到達距離, Labbé 静脈や側頭葉の損傷予防という観点 から有用と思われたので報告する。

\section{症例}

脳神経外科＼cjkstart聖麗メモリアル病院(受稿日 1997. 8. 18)〔連絡先：テ316 日立市中成沢町 1-16-10 脳神経外科 聖麗メモリアル病院 岡 部慎一〕〔Mailing address: Shinichi OKABE, M.D., Seirei Memorial Hospital for Neurosurgery, 1-16-10 Nakanarusawa-cho, Hitachi 316, Japan] 


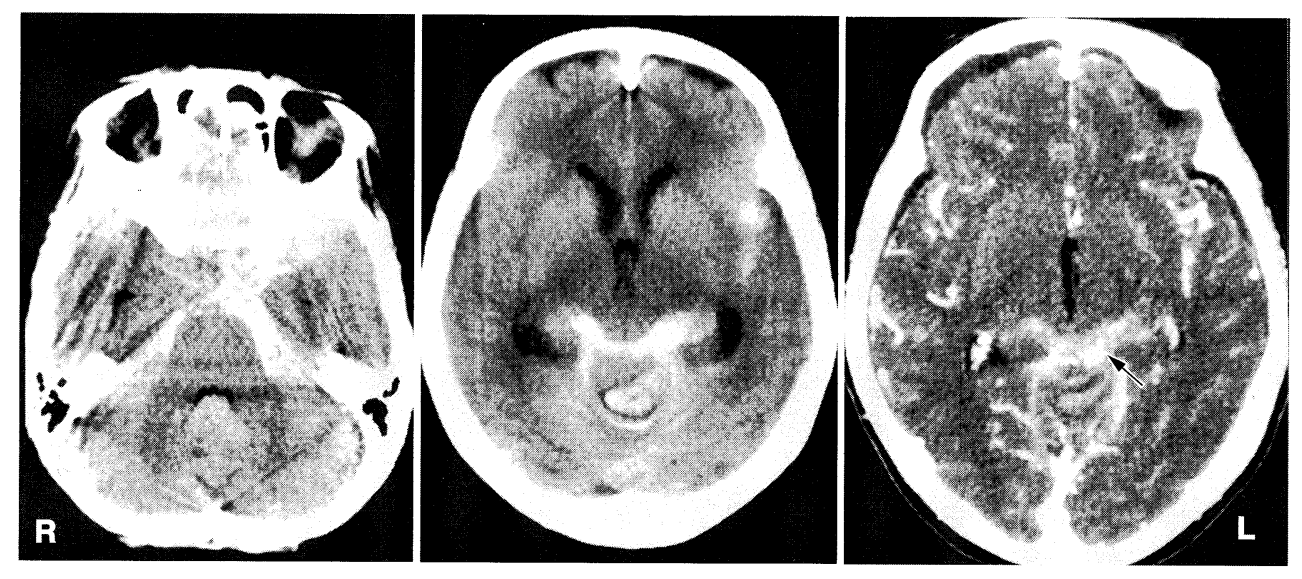

$\mathbf{A}|\mathbf{B}| \mathbf{C}$

Fig. 1 CTs on admission. A: Subarachnoid clots spread to the left Sylvian fissure. B: A small hematoma is located in the upper vermis of the cerebellum. C: Enhanced CT reveals an aneurysm in the left quadrigeminal cistern (arrow).
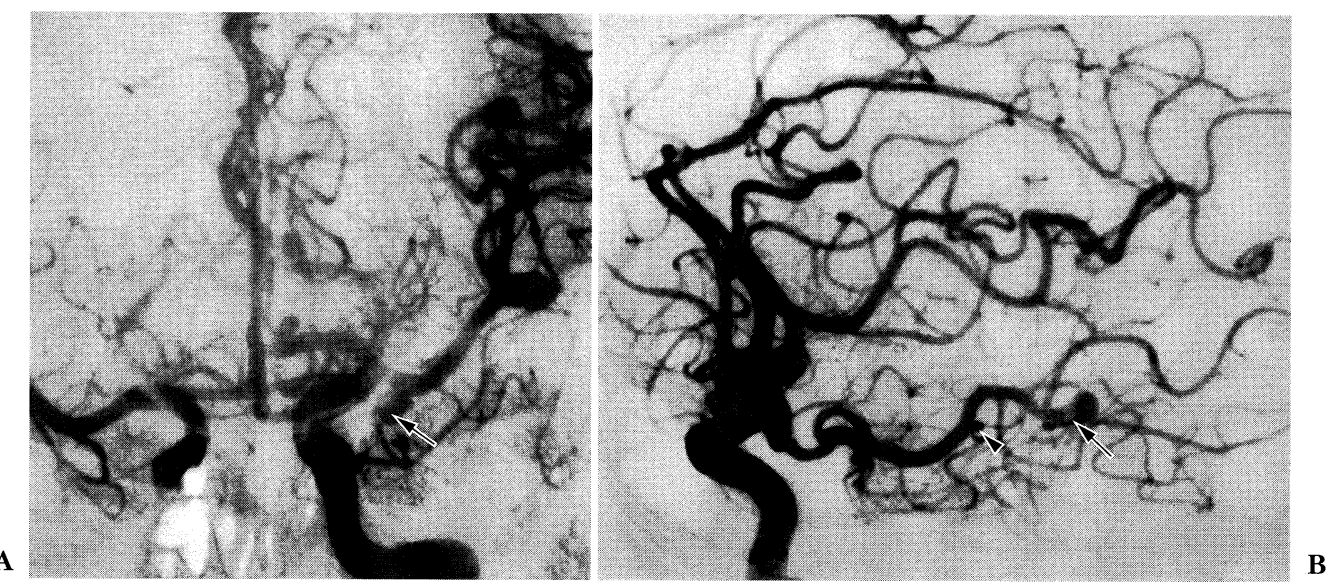

Fig. 2 Left carotid angiography. A: An aneurysm is shown on the left middle cerebral artery-anterior temporal artery junction (arrow). B: Aneurysms are shown on the $\mathrm{P}_{3}$ (arrow) and the $\mathrm{P}_{2}$ (arrowhead) segments of the left posterior cerebral artery (PCA).

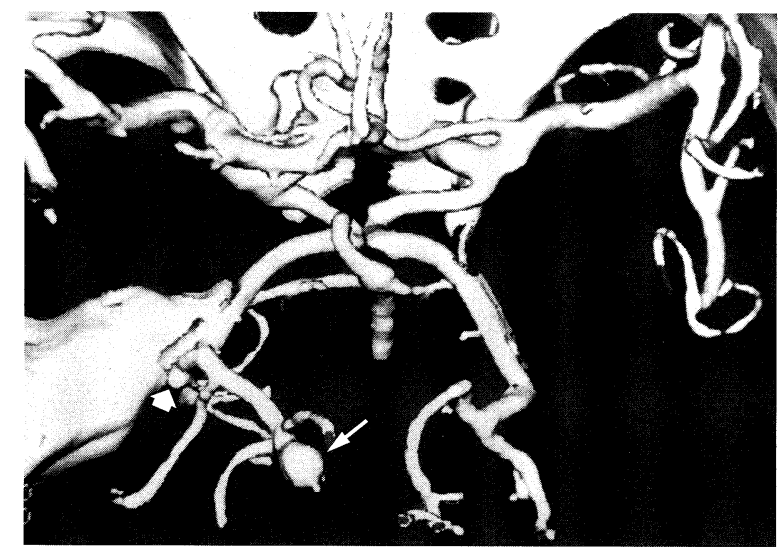

Fig. 3 3D-CTA: Posterior view of the cerebral arteries. Aneurysms of the $\mathrm{P}_{3}$ (arrow) and the $\mathrm{P}_{2}$ (arrowhead) segments are shown.
既往歴：10 年前より高血圧，内服治療中.

経 過：入浴中に突然の激しい頭痛と頸部痛を自覚し， 嘔吐が頻回で，当院へ救急搬送された。Japan Coma Scale 1 で頭痛，嘔吐，項部硬直を認めた。瞳孔不同，四肢麻痺 はなく，CTではFisher group 2であったが，左側シルビ ウス裂，後頭蓋窩に強いクモ膜下出血がみられ，小脳虫部 上部に小血腫を伴っていた。造影CTにより四丘体槽の左 上丘後方に動脈瘤の存在を示寸所見が認められた(Fig. 1A, B，C). 脳血管撮影(Fig. 2A，B)拈よび3D-CT Angiography (3D-CTA) (Fig. 3)では左後大脳動脈の鳥距動脈と頭丁真 後頭動脈分岐部 $\left(\mathrm{P}_{3}\right.$ segment $)$ に $9 \times 5 \mathrm{~mm}$ の動脈瘤と中側 頭動脈分岐部 $\left(\mathrm{P}_{2}\right.$ segment)に $2 \mathrm{~mm}$ の小動脈瘤を，また， 左中大脳動脈の前側頭動脈分岐部に $6 \times 4 \mathrm{~mm}$ の動脈瘤を 

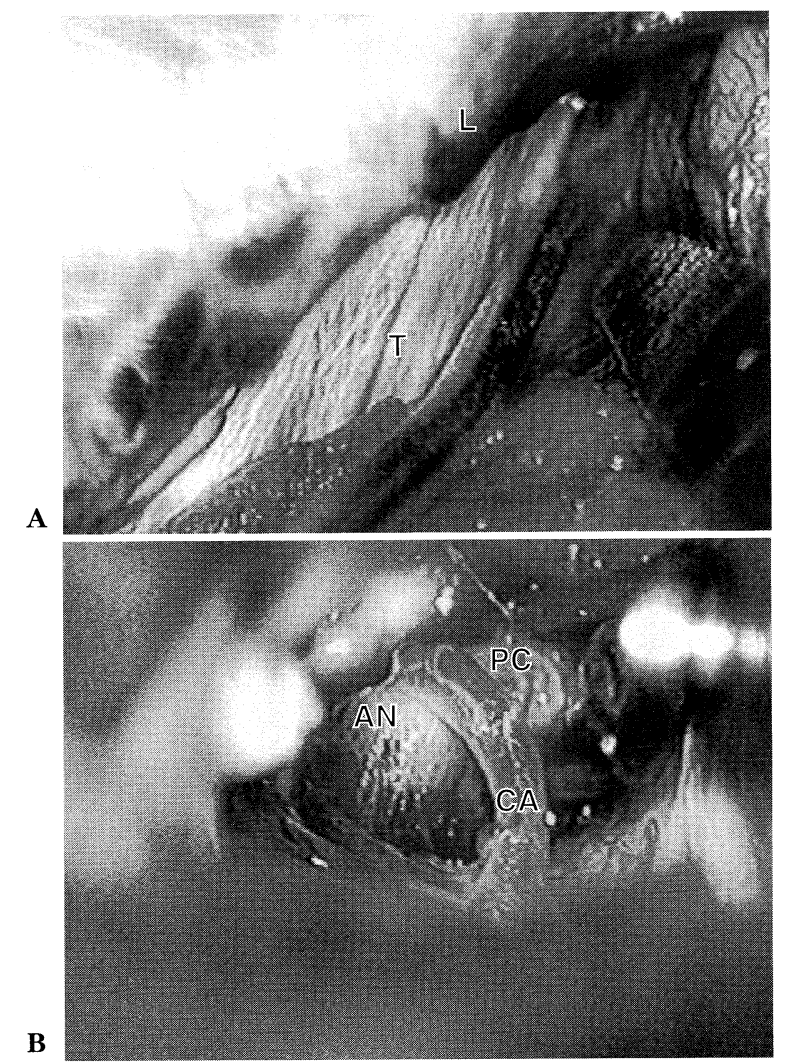

Fig. 4 Operative views. A: By the posterior subtemporal approach, we enter the space behind the vein of Labbé (L) along the tentorial surface $(\mathrm{T})$. B: A ruptured aneurysm $(\mathrm{AN})$ of the $\mathrm{P}_{3}$ segment is exposed with the PCA trunk $(\mathrm{PC})$ and the calcarine artery (CA).

認めた。破裂動脈瘤は小脳虫部の血腫より $\mathrm{P}_{3}$ に位置する 後大脳動脈瘤の可能性が強いと思われたが, 左側シルビウ ス裂に厚く広がったクモ膜下血腫の存在と動脈瘤の大き さ, 形状から左中大脳動脈瘤破裂も否定しえないと判断し た。そこで, 再手術の可能性も考慮し, 発症翌日にlumbar drainageを設置後，左pterional approachにより中大 脳動脈瘤を処置した。手術所見では未破裂であったが，シ ルビウス裂には強い血腫がみられた。動脈瘤処置後, 可及 的に血腫を洗浄除去した。術後，患者を収縮期血压 100 $\mathrm{mmHg}$ 前後の厳重な血圧管理, 鎮静のもとにおき, 初回 手術 4 日後に3D-CTAにて脳血管攣縮のないことを確認し たのち, PCAの破裂瘤 $\left(\mathrm{P}_{3}\right)$, 未破裂瘤 $\left(\mathrm{P}_{2}\right)$ を同時に clipping した。手術 approach は太い Labbé 静脈の存在, PCA に2 個の動脈瘤, 動脈瘤の向きなどの理由で, posterior subtemporal approach (PST)を選択した.

手術所見：PSTでは小脳テント上面に沿っての approachになるため(Fig. 4A), 体位は側臥位で, 左側頭

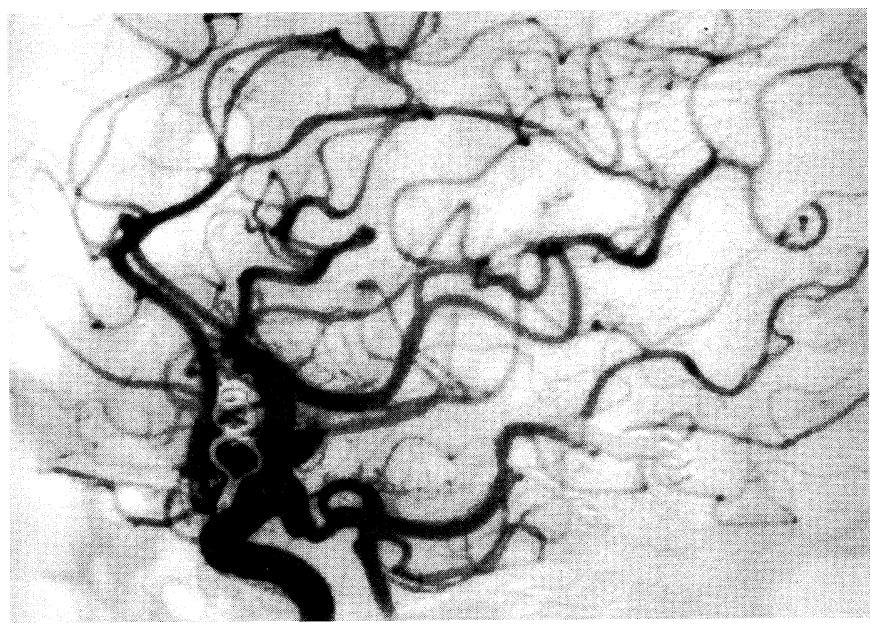

Fig. 5 Lateral view of postoperative angiography shows the well-clipped aneurysms.

後頭部テント上面が十分露出できるように開頭した。 Labbé 静脈を側頭葉から剝離したのち, Labbé 静脈の後方 から前方へ進み, まず，テント内側の滑車神経を確認し， そこで PCA 本幹 $\left(\mathrm{P}_{2}\right.$ segment)を確保した. PCA 本幹を末 梢へたどり，滑車神経がテント下へ入ったところの後方で 中脳上丘を確認した。そこから PCAが一度内側に入り再 び外側へ転じた場所に破裂動脈瘤を確認した(Fig. 4B). 動 脈溜は体部を半分ほどテント下に埋めており, working space 確保のためテントを $1 \mathrm{~cm}$ 程度切開した. 血腫の存 在から破裂点は小脳虫部に癒着していることが推定されて おり，側頭葉を引くと鳥距動脈とともにPCA 本幹が上方 へ毫引されるため強い圧排は避けた。まず, temporary clip を近位におき, 破裂瘤を clippingし, 分枝 2 本の狭窄 のないことを確認した。 その後, $\mathrm{P}_{2}$ segmentの未破裂瘤 を clipping した。

術後，側頭葉の浮腫もなく，また，脳血管攣縮による神 経症状もみられなかった。脳血管撮影ですべての動脈瘤の 消失を確認した(Fig. 5). 1 力月後, 正常圧水頭症に対して, 脳室腹腔短絡術を施行し, 患者は神経脱落症状なく, 独歩 退院した.

\section{考察}

PCAに発生する動脈瘤に対する手術approach は，その 発生部位により異なり， $\mathrm{P}_{1}$ (peduncular segment)ではfronto-temporalあるいは subtemporal, $\mathrm{P}_{2}$ (ambient segment) では subtemporal, $\mathrm{P}_{3}$ (quadrigeminal segment)では subtemporal, occipital interhemispheric, $\mathrm{P}_{4}$ (peripheral segment)では occipital interhemispheric approach が選択され る ${ }^{11) 12)}$ 。本報告では subtemporal approach を中頭蓋窩経 


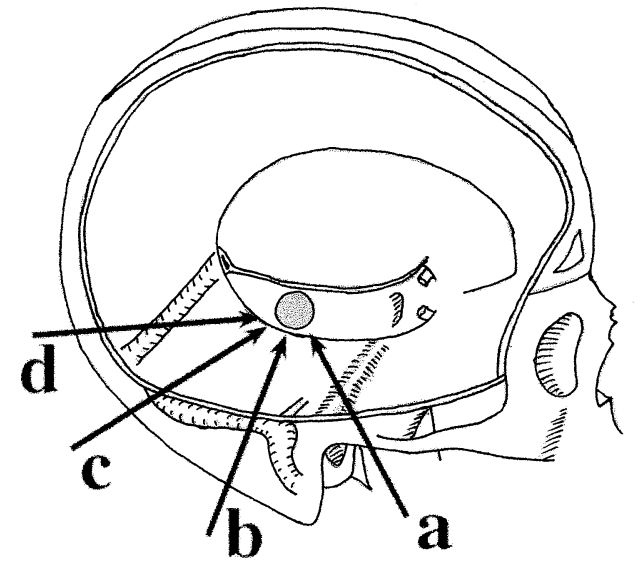

A

\begin{abstract}
Fig. 6 A: Approaches the distal posterior cerebral artery aneurysm located in the quadrigeminal cistern. a: middle subtemporal approach, b: posterior subtemporal approach, c: occipital supratentorial (transtentorial) approach, d: occipital interhemispheric approach.

B: Enhanced CT in present case. The distance to the aneurysm by the posterior subtemporal (PST) approach is shorter than by the middle subtemporal (MST) or the occipital interhemispheric (OIH) approaches.
\end{abstract}

B
由の middle subtemporal approach(MST), 自験例で採用 した側頭葉後方でテント上面経由の posterior subtemporal approach(PST)に二分した. PCA末梢 $\left(\mathrm{P}_{3}, \mathrm{P}_{4}\right)$ に位置する 動脈瘤に対しては，種々の接近方法の報告があるが 1)3)9)13)(Fig. 6A), 従来, 上記のごとく standardな $\mathrm{MST}^{1)}$ と occipital interhemispheric approach $(\mathrm{OIH})^{13)}$ が主であ ったＭSTに㧍いては，Labbé静脈の損傷を避けるため, なるべく前方から PCAに接近する方法が採られるが，㚘 骨弓をはずして，積極的に側頭葉の圧排を軽減する工夫 ${ }^{5}$ や高位迁回槽の PCA 瘤に対しては側頭葉下角を経由し, choroidal fissure を開放する方法(trans-choroidal fissure approach)が有用との報告がある ${ }^{2)}$. 自験例のように $\mathrm{P}_{3-4}$ junctionに位置する場合も含め, 迁回槽後部から四丘体槽 にある動脈瘤に対しては通常の MSTでは到達困難である 8). Yaşargil もこの部分 $\left(\mathrm{P}_{3}\right.$ segment)に対してはアクセス 不可能と述べ, OIH を推奖している ${ }^{13)}$. OIH の利点とし て, 後頭葉間隙は前頭葉間隙と異なり大脳鎌により境され ていて剝離が容易であり, bridging veinがほとんど涊め られないことがあげられる ${ }^{6)}$. 一方， 久点として視覚中枢 の線条野を直接圧排しなければならないことがあり ${ }^{377}$. これを回避するため，2つの方法が報告されている，ひと つは, 患側を下にして, 自重により後頭葉の沈下を得て, 術野を拡大しょうとするものである7 ${ }^{7}$.もう1つは同様の 開頭野に扔いて，大脳鎌からではなくテント面に沿って approachする方法である ${ }^{3)}$. 自験例の方法も後者に近いも のである.
自験例ではLabbé 静脈後方より前方に進入して, 迂回槽 においてPCA 本幹を確保したが，下方は横静脈洞まで骨 削除が行われていたので, 進入面はほほflatとなり, 手術 器具を挿入する脳表約 $1 \mathrm{~cm}$ の間隙で十分に深部の術野が 得られた。尾金ら ${ }^{9}$ もこのルートを採用し，傾頭葉の圧排 が軽減でき有用であると述べている。

自験例では，太いLabbé静脈があり，MSTでは側頭葉 の挫傷や静脈の損傷の可能性があったため, OIH も考慮 した。しかし，四丘体槽にある $\mathrm{P}_{3}$ 破裂瘤だけではなく, さらにその近位でより外側に位置する $\mathrm{P}_{2}$ 未破裂瘤の処置 をも意図したため, OIH では, PCA 近位部外側への展開 が制限され，脳の圧排が強くなると判断した．Labbé 静脈 を約 $1 \mathrm{~cm}$ にわたり，側頭葉表面から剶離し脳を圧排した。 Labbé 静脈は側頭葉の前上方から後下方へ向かっているた め, Labbé 静脈より前方での脳の圧排は小分枝とともに Labbé 静脈本幹を引くようになる。しかし, 後方での圧排 は, 直接 Labbé 静脈の長軸に沿って力が加わらないため, 十分に剝離されていれば，さほど危険な脳圧排にはならな い. また, Labbé 静脈は多くの例で横静脈洞の前 $1 / 3$ へ流 入するといわれておりり ${ }^{4)}$, Labbé 静脈の後方ではテント上 面に拈いて比較的広い術野が確保しやすい.

動脈瘤手術において，動脈瘤頸部をとらえることは重要 である.自験例での動脈藘の向きは後方であったことより， MSTによる前方からの approach ではPCA 本幹に沿って 動脈瘤をその奥にみる形となる。また，OIHでは動脈瘤 体部の奥に本幹をみることになる。本 approachではちょ 
うど動脈瘤頸部を進入方向からみる形となり, clipping 操 作が容易であり，2 分枝とも温存された。動脈瘤の向きも approach を選択するうえで重要であり，後方向きの場合 は本 approach は有用であろう。

四丘体槽への到達距離も, MSTや OIHに比し最短であ ることも利点の一つである。しかし，進入路がLabbé 静脈 より後方へ離れれば，それを損傷しにくくなるとともに， 後方に行くに従い，動脈瘤への到達距離が長くなり深部操 作を要する(Fig. 6B)，また，深部ではテントがせり上がっ てくるので，テント切開の可能性も高くなる．事実，自験 例ではworking space確保のためテント切開を要した。こ の部分では滑車神経は中脳背面上下丘間へ行っているため 切断する心配はない.

本 approachの名称についてであるが，occipito-temporal sulcus の前では posterior subtemporal approach, 後ろ では occipital supratentorial (transtentorial) approach とな る。自験例では，側面後方からで側頭葉下面とテント間の approachであったため posterior subtemporal approach と した。しかし，occipito-temporal sulcusの位置には個人 差があり 10)，一概にどちらの approachともいえない場合 がある。 occipito-temporal supratentorial approach という 名称が正確かも知れない.

四丘体槽に位置するPCA末梢動脈瘤の処置に際し，特 に多発動脈瘤などの場合は, PST は MST や OIHのオプシ ヨンとして，念頭に置いても良い方法と思われ報告した。

\section{文献}

1) Drake CG, Amacher AL: Aneurysms of the posterior cerebral artery. J Neurosurg 30: 468-474, 1969
2）池田清延，山下純宏，二見一也，ほか：脚間・迂回槽内抒 よび周囲の血管性病変に対する trans-choroidal fissure approachの手術適応：屍体による微小外科解剖の研究よ り。脳卒中の外科 23: 139-144, 1995

3) Kikuchi K, Watanabe K, Kowada M: Ruptured distal posterior cerebral artery aneurysm presenting with massive intraventricular hemorrhage-Case report一. 脳卒中の外科 20: 402-406, 1992

4) Koperna T, Tschabitscher M, Knosp E: The termination of the vein of "Labbé" and its microsurgical significance. Acta Neurochir (Wien) 118: 172-175, 1992

5）持松泰彦，藤津和彦，桑原武夫，ほか：後大脳動脈藘に対 する Zygomatic approach $-\mathrm{P}_{1}, \mathrm{P}_{2}, \mathrm{P}_{3}$ の large aneurysmの 経験からみた適応と限界一。脳卒中の外科 15: 71-75, 1987

6）馬淵正二, 上山博康, 黑田 敏, ほか：後大脳動脈遠位部 動脈瘤 $\left(\mathrm{P}_{3}\right.$ 動脈瘤)に対するoccipital interhemispheric approach. 脳卒中の外科 23: 163-166, 1995

7）中尾和民, 山田和雄, 早川 徹, ほか: Occipital approach による後大脳動脈 $\left(\mathrm{P}_{3}\right.$ 部) 動脈瘤のクリッピング一患側を下 にした側臥位の有用性一。脳卒中の外科 16: 317-320, 1988

8）西村俊彦, 福岡正晃, 小野雄弘：Subtemporal approach で は到達できなかった後大脳動脈遠位部 $\left(\mathrm{P}_{3}\right.$ portion)動脈瘤の 1例．脳神経外科 24: 1011-1014, 1996

9) 尾金一民，高橋敏夫，木村正英，ほか：後大脳動脈 $\left(\mathrm{P}_{3}\right.$ Portion)の 1 経験例。脳神経外科 19: 565-569, 1991

10）小野道夫, Yaşargil MG, Oliveira E, ほか：高位迂回槽への 側方経大脎溝・脳室到達法. 顕微鏡下手術のための脳神経 外科解剖 III 第 4 回微小脳神経外科解剖セミナー講演集, 1990, pp 65-74

11) Sakata S, Fujii K, Matsushima T, et al: Aneurysm of the posterior cerebral artery: Report of eleven cases-Surgical approaches and procedures-. Neurosurgery 32: 163-168, 1993

12) 竹前紀樹, 杉田虔一郎：後大脳動脈の手術一Subtemporal approach一。脳卒中の外科研究会 12 回講演集, $1983, \mathrm{pp}$ 300-304

13) Yaşargil MG: Microneurosurgery. Stuttgart, George Thieme Verlag, 1984, vol 2, pp 260-269 